\title{
Patient transfer influences the prognosis of pediatric patients operated for testicular torsion: a single-center experience
}

\author{
Jun Wang ${ }^{1,2 \#}$, Yongji Deng ${ }^{2 \#}$, Nannan Gu ${ }^{2 \#}$, Haobo Zhu' ${ }^{2}$, Xiaojiang Zhu' ${ }^{2}$, Liqu Huang ${ }^{2}$, Chenjun Chen ${ }^{2}$, \\ Lixia Wang ${ }^{2}$, Jun Dong, ${ }^{2}$, Yimin Yuan ${ }^{2}$, Geng $\mathrm{Ma}^{2}$, Yunfei Guo ${ }^{2}, \mathrm{Min}_{\mathrm{Gu}}{ }^{1}$ \\ ${ }^{1}$ Department of Urology, The First Affiliated Hospital of Nanjing Medical University, Nanjing, China; ${ }^{2}$ Department of Urology, Children's Hospital \\ of Nanjing Medical University, Nanjing, China \\ Contributions: (I) Conception and design: J Wang, Y Deng, L Huang, Y Guo, M Gu; (II) Administrative support: J Wang, N Gu, L Huang; (III) \\ Provision of study materials or patients: X Zhu, H Zhu, J Dong, C Chen; (IV) Collection and assembly of data: Y Deng, C Chen, L Wang, Y Yuan; (V) \\ Data analysis and interpretation: J Wang, N Gu, G Ma, X Zhu; (VI) Manuscript writing: All authors; (VII) Final approval of manuscript: All authors. \\ \#These authors contributed equally to this work. \\ Correspondence to: Min Gu. Department of Urology, The First Affiliated Hospital of Nanjing Medical University, Nanjing, China. \\ Email: njmuwzj1990@hotmail.com; Yunfei Guo. Department of Urology, Children’s Hospital of Nanjing Medical University, Nanjing, China. \\ Email: guoyunfei_nj@163.com.
}

Background: Testicular torsion (TT) remains an emerging issue for pediatric patients. This study's objective was to determine risk factors of TT outcomes in the Chinese pediatric cohort from a single center. Methods: We performed a retrospective cohort study of patients who met the inclusion criteria in our center from 2013 to 2018. Clinical demographics, and TT-related data, including laterality, torsion degree, torsion direction, position to the cavity of tunica vaginalis, enorchia, and outcomes, were reviewed and extracted from medical charts and databases. Statistical analysis was conducted to compare and figure out the risk factors of TT outcomes.

Results: A total of 84 pediatric patients were enrolled in this study. Among these variables, age, duration of symptoms, and the patient transfer were significantly associated with the outcomes of TT $(\mathrm{P}<0.005)$. Patients transferred from other medical facilities underwent more orchiectomy than those without transfer (univariate analysis, $\mathrm{P}<0.0001$; multivariate analysis, $\mathrm{P}=0.001$ ). No difference was found in other variables between patients with or without transfer $(\mathrm{P}>0.05)$. Moreover, transferred patients tended to show worse testicular function.

Conclusions: We have reported that age, duration of symptoms, and patient transfer were three significant risk factors in this cohort. Patients with transfer tended to suffer from more orchiectomy and worse prognosis of TT.

Keywords: Testicular torsion (TT); risk factors; transfer; pediatric; urology

Submitted Sep 06, 2020. Accepted for publication Jan 29, 2021.

doi: $10.21037 / \mathrm{tp}-20-287$

View this article at: http://dx.doi.org/10.21037/tp-20-287

\section{Introduction}

Testicular torsion (TT) is the most common surgical emergency in pediatric urology, often leading to organ loss and has a potential influence on fertility (1). Surgical management of TT cases should be prompt to save the affected testis and although orchiectomy is commonly performed to correct this condition, it is associated with reduced fertility $(2,3)$. Indeed, it has been reported that nearly $60 \%$ of patients who undergo orchiectomy suffer from a low sperm count for a median of 5 years (4).

Over recent decades, several studies have explored the potential indicators for predicting testicular activity during surgery and the surgical outcome. A recent cohort analysis 
of 1,625 males undergoing surgery for torsion identified the risk factors, including age and medical insurance, for orchiectomy in a population encompassing all ages (5). A cohort analysis of 2,443 boys and 152 newborns who underwent surgeries for TT found that age younger than ten years old, medical insurance, Black race, and nonemergency room admission source and surgery were independent predictors for orchiectomy (2). Moreover, the prognosis of orchiopexy was also researched in a small cohort study of 29 pediatric patients identifying mean platelet volume as an indicator for further testicular atrophy (6).

As one of the most critical pediatric medical centers in the east of China, our center is a crucial tertiary care facility for the management of urology emergencies, including TT, with over $50 \%$ of suspected TT pediatric cases transferred from other medical facilities or rural areas. The transfer process usually increases the total duration of symptoms and accentuates ischemic damage to the testicle due to prolonged access to healthcare. However, the effect of the patient transfer is ignored and remains an extensive area of study.

This study explored the risk factors for predicting the outcomes of pediatric patients diagnosed with TT, as well as those operated for TT from 2013 to 2018 in our center.

We present the following article in accordance with the STROBE reporting checklist (available at http://dx.doi. org/10.21037/tp-20-287).

\section{Methods}

\section{Ethical statement}

The study was conducted in accordance with the Declaration of Helsinki (as revised in 2013) and approved by the local Ethics Committee of Nanjing Medical University Affiliated Nanjing Children's Hospital (No. 201801172-3). All patients provided consent to participate in this study.

\section{Study population}

This study was designed as a retrospective, single-center, cohort study of pediatric patients diagnosed and operated on for TT in our center (Department of Urology, Children's Hospital of Nanjing Medical University) from 1st Jan 2013 to 30th Dec 2018. The inclusion criteria were as follows: (I) patients aged less than 18 years old; (II) patients diagnosed with TT via Color Doppler ultrasound examination in our center; (III) patients whose clinical information was available for extraction; and (IV) patients and their parents and/or guardians volunteered to participate. The exclusion criteria were: (I) patients who did not fulfill the inclusion criteria; (II) patients were enrolled in additional clinical trials; and (III) patients with missing or incomplete medical records of hospitalization.

\section{Data extraction}

The following variables were obtained from medical charts and database during hospitalization: age at presentation, cause of TT, misdiagnosed TT, duration of symptoms, patient transfer, season/date/time at presentation, laterality, degree, and direction of torsion, position relative to the cavity of the tunica vaginalis, enorchia, and outcomes (orchidopexy/orchiectomy). Among these, the degree and direction of the torsion, as well as the position to the cavity of tunica vaginalis and enorchia, were obtained from the Color Doppler ultrasound examination reports. Patient transfer was defined as patients transferred from other medical facilities other than Nanjing city by their parents or ambulance and the transfer process typically took more than 2 hours. The time at presentation was classified as daytime (8:00 AM to 5:30 PM) and nighttime (5:30 PM to 8:00 $\mathrm{AM}$ ), while the season was classified as spring (March-May), summer (June-August), autumn (September-November), and winter (December-February). Once the diagnosis of TT was confirmed by ultrasound, surgery was performed under general anesthesia and in the supine position. The testis was checked after making an incision in the skin of the scrotum. Orchidopexy was performed to release the torsion, with orchiectomy performed if the testicular blood flow was not restored. All surgical procedures were performed by the two authors (Jun Wang and Yongji Deng). The data were extracted by two independent authors (Jun Wang and Haobo Zhu), and discrepancies were resolved by the third author (Min $\mathrm{Gu})$.

\section{Statistical analysis}

All quantitative data were presented as mean \pm standard deviation (SD). Student's $t$-test, Chi-square tests, and Fisher's exact test were conducted to compare the differences between the two groups. Multivariable linear logistic regression analysis was used to explore the risk factors in our cohort. A P value less than 0.05 was regarded 
Table 1 Details of patients with testicular torsion (TT)

\begin{tabular}{|c|c|}
\hline Variables & Patients with $\Pi \mathrm{T}$ \\
\hline Case number (n) & 84 \\
\hline Age (years; mean \pm SD) & $7.82 \pm 5.42$ \\
\hline \multicolumn{2}{|l|}{ Cause of TT } \\
\hline Trauma (n; \%) & $6(7.14)$ \\
\hline Unknown (n; \%) & $78(92.86)$ \\
\hline Missed diagnosis of TT (n; \%) & $9(10.71)$ \\
\hline Duration of symptoms (days; mean $\pm \mathrm{SD}$ ) & $2.33 \pm 2.98$ \\
\hline Patient transfer (n; \%) & $54(64.28)$ \\
\hline \multicolumn{2}{|l|}{ Season } \\
\hline Spring (n; \%) & $14(16.67)$ \\
\hline Summer (n; \%) & $25(29.76)$ \\
\hline Autumn (n; \%) & $24(28.57)$ \\
\hline Winter (n; \%) & $21(25.00)$ \\
\hline \multicolumn{2}{|l|}{ Date } \\
\hline Monday (n; \%) & $13(15.48)$ \\
\hline Tuesday (n; \%) & $11(13.10)$ \\
\hline Wednesday (n; \%) & $8(9.52)$ \\
\hline Thursday (n; \%) & $14(16.67)$ \\
\hline Friday (n; \%) & $7(8.33)$ \\
\hline Saturday (n; \%) & $17(20.23)$ \\
\hline Sunday (n; \%) & $14(16.67)$ \\
\hline \multicolumn{2}{|l|}{ Time } \\
\hline Daytime (n; \%) & $35(41.67)$ \\
\hline Nighttime (n; \%) & $49(58.33)$ \\
\hline \multicolumn{2}{|l|}{ Laterality } \\
\hline Right side (n; \%) & $20(23.81)$ \\
\hline Left side $(\mathrm{n} ; \%)$ & $64(76.19)$ \\
\hline Torsion degree (degree; mean \pm SD) & $515.36 \pm 219.28$ \\
\hline \multicolumn{2}{|l|}{ Torsion direction } \\
\hline Clockwise (n; \%) & $54(64.28)$ \\
\hline Anticlockwise (n; \%) & $30(35.71)$ \\
\hline \multicolumn{2}{|l|}{ Position to cavity of tunica vaginalis } \\
\hline Inside (n; \%) & 77 (91.67) \\
\hline Outside (n; \%) & $7(8.33)$ \\
\hline Enorchia (n; \%) & $3(3.57)$ \\
\hline \multicolumn{2}{|l|}{ Outcome } \\
\hline Orchidopexy (n; \%) & $21(25.00)$ \\
\hline Orchiectomy (n; \%) & $63(75.00)$ \\
\hline
\end{tabular}

$\mathrm{SD}$, standard deviation. as statistically significant and all statistical analysis was performed in the SPSS 13.0 software (SPSS Inc., Chicago, IL, USA).

\section{Results}

Overall, a total of 84 boys diagnosed with TT visited our center and underwent surgical procedures after hospitalization. The primary characteristics of the patients are presented in Table 1 . The mean age of the patients was 7.82 years old (age range, from 2 days to 14 years) and more than $60 \%$ of patients (54/84) were transferred from other medical facilities. Unfortunately, the collection of the transfer-related data, such as transfer distance, degree of medical facilities, and time of delay were not possible due to missing data in medical charts. The mean duration of symptoms was 2.33 days, with 21 patients undergoing orchidopexy and 63 patients underwent orchiectomy.

To determine the factors influencing the surgical procedures, the patients were classified into two groups depending on whether they underwent orchidopexy or orchiectomy and the results of the univariate analysis are shown in Table 2. In the orchidopexy group, the mean age of patients was significantly higher than the orchiectomy group $(\mathrm{P}=0.002)$, with a shorter duration of symptoms $(\mathrm{P}=0.009)$, and fewer patients were transferred from other facilities $(\mathrm{P}<0.0001)$. There was no statistical difference in other variables between the two groups $(\mathrm{P}>0.05)$. A multivariate analysis of the two groups was performed and the results are presented in Table 3. Similarly, age, duration of symptoms, and patient transfer significantly correlated with the surgical procedures (age, $\mathrm{P}=0.006$; duration of symptoms, $\mathrm{P}=0.005$; patient transfer, $\mathrm{P}=0.009$ ). Also, the date of admission to our center was related to the outcomes $(\mathrm{P}=0.036)$, with age, duration of symptoms, and patient transfer significantly contributing to surgical procedures and patient outcomes.

Further analysis of patients with or without transfer after the diagnosis of TT was performed as shown in Table 4, revealing significant differences in patients' outcomes in both the univariate and multivariate analyses (univariate analysis, $\mathrm{P}<0.0001$; multivariate analysis, $\mathrm{P}=0.001$ ). However, there was no difference between patients with or without transfer in the other variables.

During the 1-year follow-up after surgery, two cases of atrophia testiculi were reported among five patients who underwent orchidopexy in the transfer group. 
Table 2 Comparison between patients underwent orchidopexy and orchiectomy.

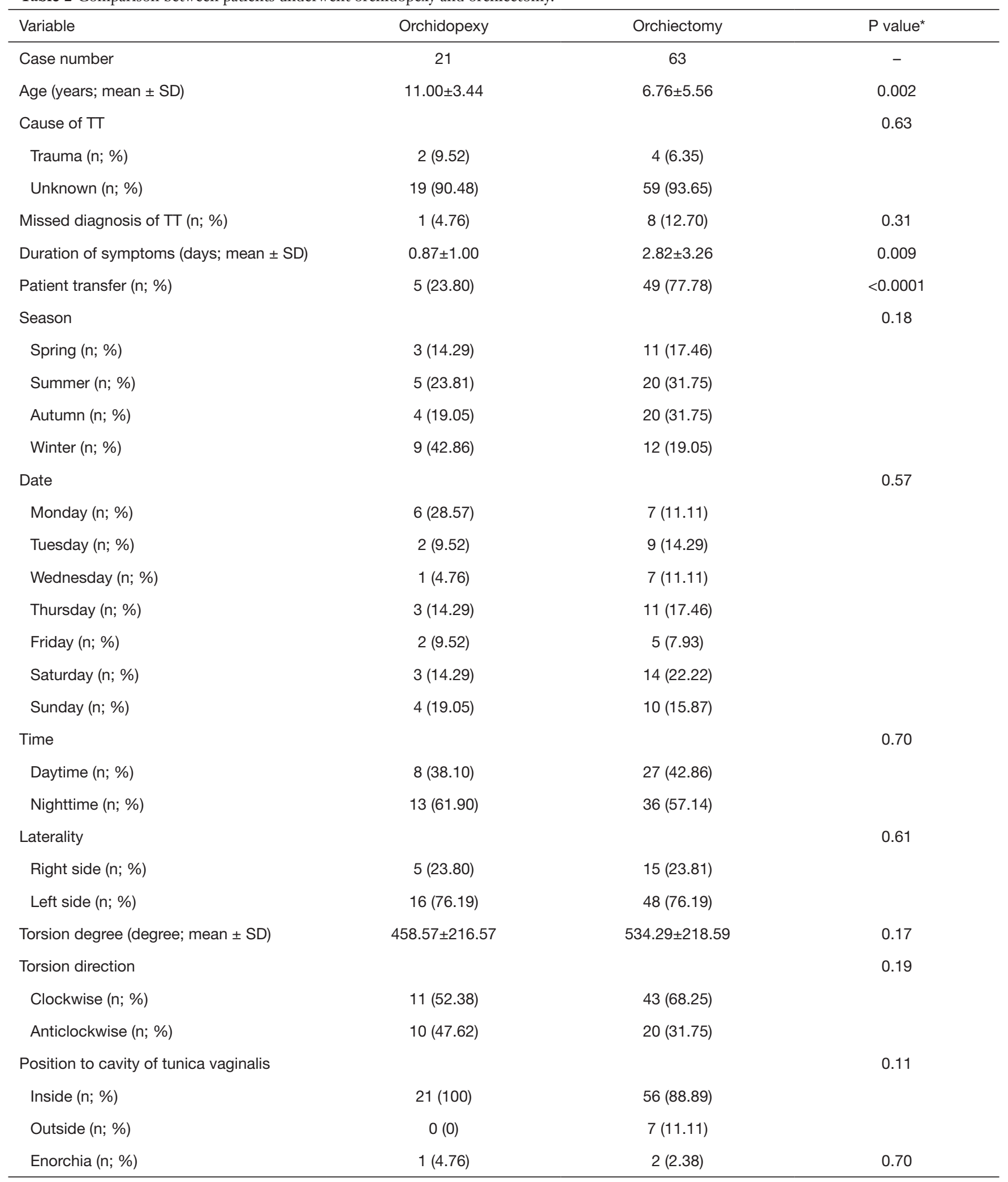

${ }^{*} \mathrm{P}$ value was calculated by Student t test or Chi's test. SD, standard deviations; TT, testicular torsion. 
Table 3 Results of multivariable analysis between patients underwent orchidopexy and orchiectomy by logistic regression analysis

\begin{tabular}{lcc}
\hline Variables & P value & OR (95\% Cl) \\
\hline Age & 0.006 & $1.39(1.10-1.75)$ \\
Cause of TT & 0.44 & $5.03(0.086-294.54)$ \\
Missed diagnosis of TT & 0.26 & $7.82(0.23-271.72)$ \\
Duration of symptoms & 0.005 & $0.11(0.024-0.52)$ \\
Patient transfer & 0.009 & $0.08(0.012-0.54)$ \\
Season & 0.20 & $1.77(0.74-4.27)$ \\
Date & 0.036 & $0.58(0.35-0.96)$ \\
Time & 0.64 & $0.63(0.092-4.34)$ \\
Laterality & 0.37 & $3.01(0.27-34.19)$ \\
Torsion degree & 0.34 & $1.00(0.99-1.00)$ \\
Torsion direction & 0.39 & $0.39(0.047-3.27)$ \\
Position to cavity of tunica vaginalis & 1.00 & $1.55 \times 10^{-8}($ reference $)$ \\
Enorchia & 0.51 & $6.16(0.027-1.39)$ \\
\hline
\end{tabular}

$\Pi$, testicular torsion; OR, odds ratio; $\mathrm{Cl}$, confidential interval.

Table 4 Comparison between TT patients with or without transfer treatment

\begin{tabular}{|c|c|c|c|c|c|}
\hline Variables & Transfer & No transfer & $\begin{array}{l}\text { P value from } \\
\text { univariate } \\
\text { analysis }\end{array}$ & $\begin{array}{l}\mathrm{P} \text { value from } \\
\text { multivariate } \\
\text { analysis }\end{array}$ & $\begin{array}{c}\text { OR }(95 \% \mathrm{Cl}) \\
\text { from multivariate } \\
\text { analysis }\end{array}$ \\
\hline Age (years; mean \pm SD) & $7.40 \pm 5.47$ & $8.58 \pm 5.33$ & 0.29 & 0.94 & $1.01(0.89-1.13)$ \\
\hline Missed diagnosis of TT (n; \%) & $8(14.81)$ & $1(3.33)$ & 0.10 & 0.32 & $3.80(0.27-52.71)$ \\
\hline Laterality & & & 0.54 & 0.58 & $0.68(0.18-2.63)$ \\
\hline Right side (n; \%) & $14(25.93)$ & $6(20.00)$ & & & \\
\hline Left side (n; \%) & $40(74.07)$ & $24(80.00)$ & & & \\
\hline Torsion degree (degree; mean \pm SD) & $511.67 \pm 179.85$ & $522.00 \pm 280.05$ & 0.15 & 0.44 & 1.00 (reference) \\
\hline Anticlockwise (n; \%) & $17(31.49)$ & $13(43.33)$ & & & \\
\hline Position to cavity of tunica vaginalis & & & 0.68 & 0.99 & $1.01(0.11-9.2)$ \\
\hline Inside (n; \%) & $49(90.74)$ & $28(93.33)$ & & & \\
\hline Outside (n; \%) & $5(9.26)$ & $2(6.67)$ & & & \\
\hline Enorchia (n; \%) & $1(1.85)$ & $2(6.67)$ & 0.26 & 0.73 & $0.58(0.028-12.05)$ \\
\hline Outcome & & & $<0.0001$ & 0.001 & $0.10(0.024-0.42)$ \\
\hline Orchidopexy (n; \%) & $5(9.26)$ & $16(53.33)$ & & & \\
\hline Orchiectomy (n; \%) & $49(90.74)$ & $14(46.67)$ & & & \\
\hline
\end{tabular}

$\mathrm{SD}$, standard deviations; TT, testicular torsion; OR, odds ratio; $\mathrm{Cl}$, confidential interval. 


\section{Discussion}

Our study included a total of 84 pediatric patients diagnosed with TT who underwent surgery in our center. For this cohort, age, duration of symptoms, and patient transfer were independent risk factors, with patients transferred from other medical facilities tending to undergo orchiectomy, and the prognosis of transferred patients who underwent orchidopexy was relatively poor.

Numerous studies have investigated the risk factors of TT in pediatric and adult patients showing that patient age is an important risk factor for the occurrence of TT. A recent retrospective cohort study including 1,625 males undergoing surgery for torsion, reported that the risk of orchiectomy was highest in patients aged 1-11 years old and aged over 50 years old (7). Limited to pediatric patients under 18 years old, the age distribution is also considered bimodal, with one peak in the first-year period and the second peak around puberty. This is associated with poorer fixation (8). There was a similar age distribution in our study, with 16 of 84 cases (19\%) aged less than one, and 44 of 84 cases $(52.38 \%)$ around puberty. However, considering that some children around puberty underwent procedures at local medical facilities, the proportion of older children in this cohort may be larger.

Furthermore, seasonal alternations have also been reported contributing to the occurrence of TT, with the highest incidence of TT correlated to cold weather $(9,10)$. However, this study did not observe any seasonal variation. In previous studies with positive climatic results, most pediatric patients lived in cold areas, such as New York and Austria, where the mean temperature was remarkably lower than in east China. Also, the incidence of TT was related but not limited to the outdoor temperature, which was also associated with the indoor temperature, housing, and clothing conditions. Similarly, we did not find any differences in the time of visit (daytime or nighttime) or day of the week, which can also be explained by various confounding factors.

The duration of symptoms was significantly associated with the outcome of TT: the longer the duration of symptoms, the more cases of orchiectomy were performed. Nevertheless, it was apparent that the degree of TT did not contribute to the outcome of TT. The selection of surgery for patients with TT was dependent on the severity of testicular ischemia, which was determined by various risk factors, including duration of symptoms, degree of TT, and fixation of testicular tissues (11). A single-center retrospective study involving 165 children reported that duration of symptoms longer than 6 hours, a degree torsion of more than $180^{\circ}$, and white blood count were predictive factors for a non-salvageable testis (12). Previous studies also supported the strong relationship between the degree of TT and the salvage rate (13-15). In this study, the degree of TT was reported by Color Doppler ultrasound, a useful tool for the clinical assessment and diagnosis of TT, but should be interpreted with caution due to a certain amount of error (16). The degree of TT can rarely be determined without immediate surgical exploration (8) and the surgical technique and post-operative treatment have developed dramatically in pediatric urology. The degree of TT was not a crucial factor for surgery selection in our center, though the duration of symptoms was significant.

Importantly, transferred patients had a significantly higher incidence of orchiectomy and poor prognosis of orchidopexy than non-transferred patients in this study. In east China, there are limited centers capable of performing surgery on pediatric patients diagnosed with TT, especially patients under one-year-old. Furthermore, TT is often misdiagnosed as acute appendicitis or chordapsus, thereby contributing to the duration of symptoms and the rate of transfer. Other studies have also recognized the importance of a shorter transfer time for pediatric patients to the operating room, a serious issue in developing countries (17).

Overholt et al. (18) retrospectively reviewed 23 cases of pediatric patients with TT, concluding that patients who lived in rural areas might have an increased likelihood for adverse outcomes, which can result in lifelong complications for the affected individuals. However, this study only focused on the impact of the transfer on the outcomes in a limited number of patients, and various confounding factors were ignored, resulting in a substantial confounding bias.

This study has several limitations. Firstly, some additional potential risk factors were not included for extensive analysis, such as medical insurance and distance of transfer. Secondly, our analysis did not encompass longterm follow-up, hence the predictor factors of long-term outcomes remain unexplored. Moreover, the study design was a retrospective cohort study and restricted the accuracy of results, therefore, a prospective, well-designed, and largescale study should be conducted.

In conclusion, this study involved a total of 84 pediatric patients in a single-center, showing that age, duration of symptoms, and patient transfer were significant risk factors for the outcomes of TT. Besides, patients transferred from other medical facilities tended to undergo orchiectomy and 
had a comparatively poorer prognosis of orchidopexy than non-transferred patients.

\section{Acknowledgments}

Funding: This work was supported by the National Natural Science Foundation of China (grant numbers 81870512, 81570676), Project of Jiangsu Province for Important Medical Talent (grant number ZDRCA2016025).

\section{Footnote}

Reporting Checklist: The authors have completed the STROBE reporting checklist. Available at http://dx.doi. org/10.21037/tp-20-287

Data Sharing Statement: Available at http://dx.doi. org/10.21037/tp-20-287

Conflicts of Interest: All authors have completed the ICMJE uniform disclosure form (available at http://dx.doi. org/10.21037/tp-20-287). The authors have no conflicts of interest to declare.

Ethnic Statement: The authors are accountable for all aspects of the work in ensuring that questions related to the accuracy or integrity of any part of the work are appropriately investigated and resolved. The study was conducted in accordance with the Declaration of Helsinki (as revised in 2013). The study was approved by the local Ethics Committee of Nanjing Medical University Affiliated Nanjing Children's Hospital (No. 201801172-3) and informed consent was taken from all the patients.

Open Access Statement: This is an Open Access article distributed in accordance with the Creative Commons Attribution-NonCommercial-NoDerivs 4.0 International License (CC BY-NC-ND 4.0), which permits the noncommercial replication and distribution of the article with the strict proviso that no changes or edits are made and the original work is properly cited (including links to both the formal publication through the relevant DOI and the license). See: https://creativecommons.org/licenses/by-nc-nd/4.0/.

\section{References}

1. Erdogan $\mathrm{O}$, Cetinkaya $\mathrm{M}$, Sahin $\mathrm{H}$, et al. Investigation of the protective effect of nesfatin-1 on testicular ischaemia- reperfusion damage: An experimental study. Andrologia 2020;52:e13769.

2. Zhao LC, Lautz TB, Meeks JJ, et al. Pediatric testicular torsion epidemiology using a national database: incidence, risk of orchiectomy and possible measures toward improving the quality of care. J Urol 2011;186:2009-13.

3. Lee SM, Huh JS, Baek M, et al. A nationwide epidemiological study of testicular torsion in Korea. J Korean Med Sci 2014;29:1684-7.

4. Ferreira U, Netto Junior NR, Esteves SC, et al. Comparative study of the fertility potential of men with only one testis. Scand J Urol Nephrol 1991;25:255-9.

5. Greear GM, Romano MF, Katz MH, et al. Testicular torsion: epidemiological risk factors for orchiectomy in pediatric and adult patients. Int J Impot Res 2020. [Epub ahead of print]. doi: 10.1038/s41443-020-0331-8

6. He M, Li M, Zhang W. Prognosis of testicular torsion orchiopexy. Andrologia 2020;52:e13477.

7. Horn G, Romano M, Munarriz R, et al. Testicular Torsion: Epidemiological Risk Factors for Orchiectomy in Pediatric and Adult Patients. J Sexual Med 2016;13:S25.

8. Sharp VJ, Kieran K, Arlen AM. Testicular torsion: diagnosis, evaluation, and management. Am Fam Physician 2013;88:835-40.

9. Saxena AK, Castellani C, Ruttenstock EM, et al. Testicular torsion: a 15-year single-centre clinical and histological analysis. Acta Paediatrica 2012;101:e282-6.

10. Srinivasan AK, Freyle J, Gitlin JS, et al. Climatic conditions and the risk of testicular torsion in adolescent males. J Urol 2007;178:2585-8; discussion 2588.

11. Kyriazis ID, Dimopoulos J, Sakellaris G, et al. Extravaginal testicular torsion: a clinical entity with unspecified surgical anatomy. Int Braz J Urol 2008;34:617-23; discussion 623-6.

12. Tanaka K, Ogasawara Y, Nikai K, et al. Acute scrotum and testicular torsion in children: a retrospective study in a single institution. J Pediatr Urol 2020;16:55-60.

13. Boettcher M, Bergholz R, Krebs TF, et al. Clinical predictors of testicular torsion in children. Urology 2012;79:670-4.

14. Boettcher M, Krebs T, Bergholz R, et al. Clinical and sonographic features predict testicular torsion in children: a prospective study. BJU Int 2013;112:1201-6.

15. Yang C, Song B, Tan J, et al. Testicular torsion in children: a 20-year retrospective study in a single institution. TheScientificWorldJournal 2011;11:362-8. 
16. Baker LA, Sigman D, Mathews RI, et al. An analysis of clinical outcomes using color doppler testicular ultrasound for testicular torsion. Pediatrics 2000;105:604-7.

17. Dias ACF, Maroccolo MVO, Ribeiro HdP, et al. Presentation delay, misdiagnosis, inter-hospital transfer times and surgical outcomes in testicular torsion: analysis of statewide case series from central Brazil. Int Braz J Urol 2020;46:972-81.

18. Overholt T, Jessop M, Barnard J, et al. Pediatric testicular torsion: does patient transfer affect time to intervention or surgical outcomes at a rural tertiary care center? BMC Urol 2019;19:39.

Cite this article as: Wang J, Deng Y, Gu N, Zhu H, Zhu X, Huang L, Chen C, Wang L, Dong J, Yuan Y, Ma G, Guo Y, Gu $M$. Patient transfer influences the prognosis of pediatric patients operated for testicular torsion: a single-center experience. Transl Pediatr 2021;10(3):494-501. doi: 10.21037/tp-20-287 